\title{
Balanço hídrico de uma bacia hidrográfica localizada no oeste do estado do Paraná
}

\author{
Water balance of a river basin located in the west of the state of Paraná, Brazil

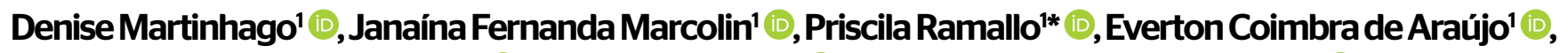

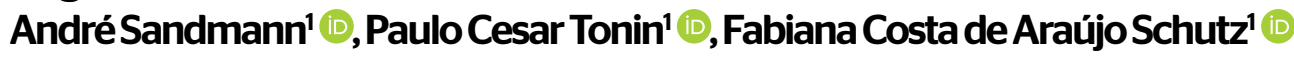

\section{RESUMO}

Balanço hídrico é uma análise realizada com base em estudos sobre as entradas e saídas de água de uma bacia hidrográfica, e que tem grande importância por identificar o regime hidrológico e as possibilidades de utilização da bacia. Neste trabalho foi realizado o balanço hídrico de uma secção de bacia hidrográfica localizada no oeste do Paraná, em uma área de plantio de eucaliptos para corte, obtendo-se também os valores para o escoamento superficial por meio do método racional.

Palavras-chave: hidrologia; método racional; escoamento superficial.

\begin{abstract}
Water balance consists in an analysis carried out based on studies on the inflows and outflows of a hydrographic basin, which is fundamental to identify the hydrological regime and the possibilities of using this basin. This study aims to verify the water balance of a section of a hydrographic basin located in Western Paraná, Brazil, in addition to obtaining the values for runoff by the rational method.
\end{abstract}

Keywords: hydrology; rational method; surface runoff.

\section{INTRODUÇÃO}

O homem, desde a sua criação, convive diariamente com os ecossistemas e as condições naturais do planeta Terra, tanto para seu próprio desenvolvimento quanto para seu uso. Não é de hoje que existe uma preocupação com o ciclo das águas: há relatos de que em 100 a.C., aproximadamente, Vitruvius tentou explicar, ainda que erroneamente, os conceitos do ciclo hidrológico. Mesmo com o pouco conhecimento que se tinha sobre de onde e como vinham as águas e sobre seu ciclo, já que na época se acreditava que o mar alimentava os rios por meio de forças subterrâneas, as antigas civilizações conseguiram construir grandiosas obras para melhorar a qualidade de vida da população e as suas plantações (TUCCI, 2009).

A água sempre ocupou um lugar de destaque entre os recursos naturais que são indispensáveis ao homem. Ela é responsável por conter o equilíbrio da vida no planeta em que habitamos. Com o crescimento desenfreado dos centros urbanos e a expansão demográfica e industrial, existe uma necessidade cada vez maior de utilização desses recursos. Muitas vezes a água não está disponível na quantidade em que é necessária. Os resultados que se obtêm desse fato são o impacto ambiental e a má qualidade desse recurso tão indispensável para a vida humana (FILL et al., 2005).

Com o passar dos anos, realizaram-se pesquisas e obtiveram-se conhecimentos sobre as áreas ambiental e hídrica, porém as preocupações com a água só aumentaram. Com isso, foram sendo estabelecidas novas metas para tentar minimizar os prejuízos que o homem vem causando à natureza (ANA, 2012).

O balanço hídrico é um dos estudos que podem ser realizados sobre as temáticas ambiental e hídrica. Trata-se de uma análise do ciclo hidrológico, cujos resultados mostram a quantidade de água que o sistema possui apresentando um ciclo fechado (FILL et al., 2005).

Nesse contexto, para que seja possível realizar uma avaliação com maior exatidão de resultados do balanço hídrico, é necessária uma análise da variação de tempo das quantidades de água superficial e subterrânea armazenadas em uma bacia hidrográfica e também os seus respectivos fluxos, como evapotranspiração, escoamento e precipitação. Com base nisso, é possível extraírem-se grandes informações a respeito do regime hídrico e das suas possibilidades de utilização para essa bacia hidrográfica (FILL et al., 2005).

Para este estudo, foi realizada uma pesquisa sobre uma pequena fatia de um rio localizado na região oeste do estado do Paraná, em uma área de preservação ambiental e reflorestamento. Para ele, foi produzido um balanço hídrico a fim de serem levantadas as informações para o cálculo de escoamento superficial com o método racional, obtendo-se a vazão dessa parcela e a influência que ela exerce sobre o escoamento final do rio. 


\section{METODOLOGIA}

A área do estudo compreende uma parcela do Rio Xaxim de aproximadamente $1.501,24 \mathrm{~km}$, situada praticamente na metade da sua extensão, afluente escolhido para a realização do estudo. O Rio Xaxim está situado na região oeste do estado do Paraná, mais precisamente no município de Matelândia. Compreende uma área de 213,89 hectares e possui vazão estimada para essa área de aproximadamente $3.500 \mathrm{~m}^{3} \cdot \mathrm{h}^{-1}$, conforme se pode visualizar na Figura 1 .

A Figura 1 traz a geolocalização do trecho escolhido, com a demarcação do perímetro da área de estudo, que compreende uma reserva florestal composta especificamente de árvores de Eucalyptus. O trecho afluente fica localizado no interior dessa área de reflorestamento e exerce uma influência no estudo.

No balanço hídrico desse trecho do Rio Xaxim foi utilizada a metodologia aplicada por Fill et al. (2005), considerando-se como base para cálculo a Equação 1.

$P+Q_{S I}+Q_{U I}-\left(E T+Q_{S O}+Q_{U O}\right)=\Delta S$

Em que:

$P=$ a precipitação média no período;

$Q_{S I}=$ a vazão de entrada superficial;

$Q_{U I}=$ a contribuição subterrânea;

$E T$ = a evapotranspiração;

$Q_{S O}=$ a vazão de saída de água superficial;

$Q_{U O}=$ a vazão de saída de água subterrânea, tudo medido em milímetros (FILL et al., 2005)
Para bacias que não estejam localizadas em áreas de recarga de aquíferos profundos ou em regiões cársticas, como é o caso do Rio Xaxim, os termos referentes aos fluxos subterrâneos $\left(Q_{U O}\right)$ são pequenos e podem ser desprezados na presença dos demais termos. Assim, a Equação 1 resulta na Equação 2

$\Delta S=P+Q_{S I}-E T-Q_{S O}$

A estimativa do influxo superficial $\left(Q_{S I}\right)$ representa o despejo de águas residuárias. Como o Rio Xaxim não possui despejo de águas residuárias, o $Q_{S I}$ também é desconsiderado. Assim, a Equação 2 para o cálculo do balanço hídrico pode ser escrita como a Equação 3:

$\Delta S=P-E T-Q_{S O}$

O balanço hídrico $(\Delta S)$ pode ser entendido como o resultado da quantidade de água que entra e sai de um sistema em um determinado intervalo de tempo, considerando-se os seus respectivos fluxos, como evapotranspiração $\left((E T=E)\right.$, escoamento $\left(Q_{S O}=Q\right)$ e precipitação $(P)$ (FILL et al., 2005). Portanto, para encontrar os valores desses fluxos, será empregada a Equação 4:

$P=E+Q$

Segundo Leopoldo et al. (1982), a evapotranspiração $(E)$ pode ser obtida pela Equação 5:

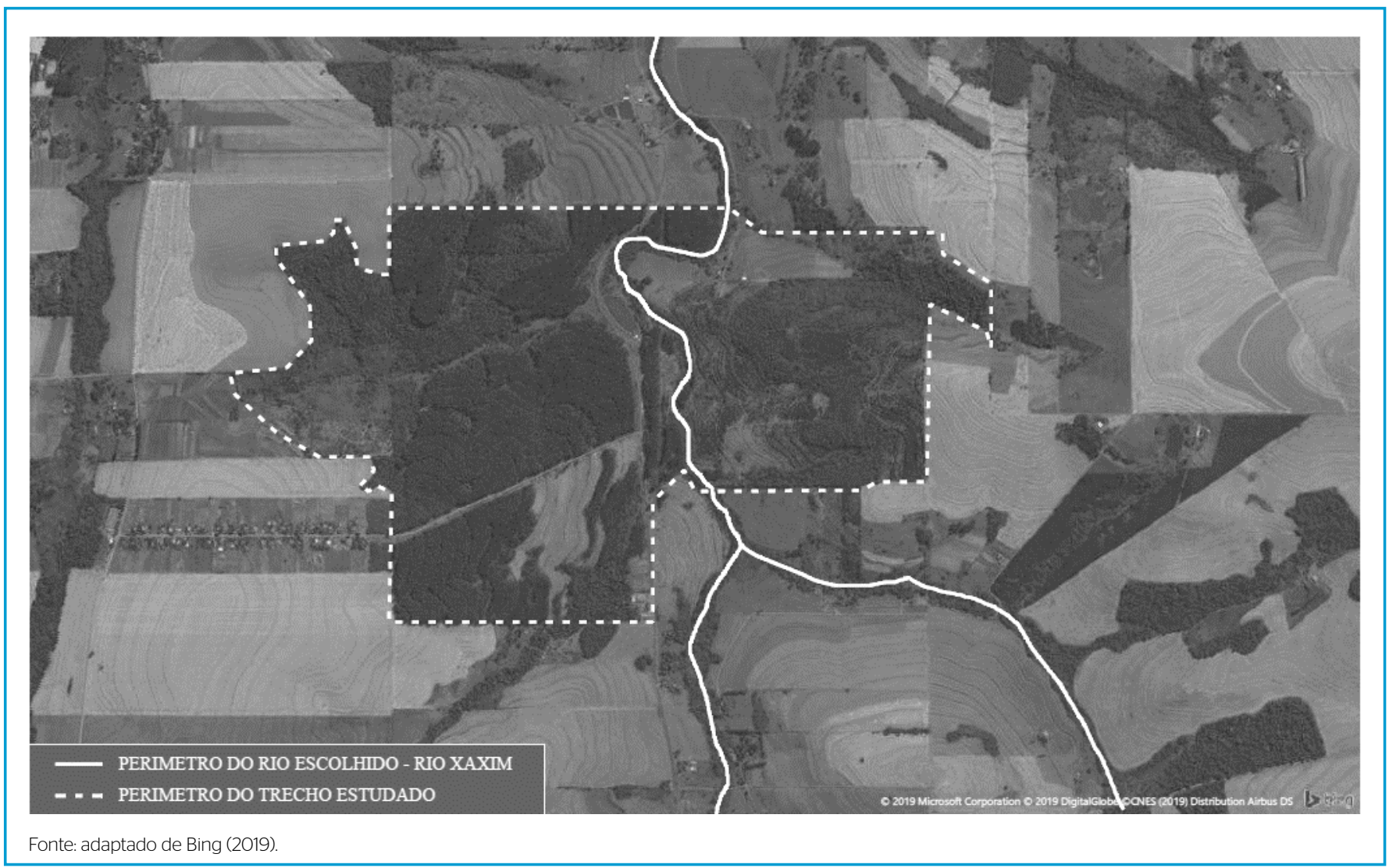

Figura 1 - Localização de área escolhida para estudo. 
$E=I+T$

Em que:

$I=$ a perda por interceptação;

$T$ = a transpiração. Portanto, a Equação 4 pode ser escrita como a Equação 6 :

$P=I+T+Q$

Assim, para a estimativa da perda por interceptação $(I)$, será utilizado o valor encontrado por Sari et al. (2016) no estudo em que eles analisaram a interceptação da chuva em duas florestas de mata nativa características do bioma Mata Atlântica e uma floresta de eucalipto, ambas localizadas na região Sul do Brasil.

Para estimar a perda por interceptação, eles usaram a Equação 7:

$I=P T-\left(P I+E_{T}\right)$

Em que:

$I=$ a perda por interceptação;

$P T=$ a precipitação total;

$P l=$ a precipitação interna;

$E_{T}=$ o escoamento pelo tronco.

O que interessa para esta pesquisa são os resultados com a floresta de eucalipto, e a perda por interceptação (I) estimada foi de $14,56 \%$ da precipitação total para essa floresta (SARI et al., 2016).

Para o cálculo da transpiração, foi utilizada a metodologia apontada por Leopoldo et al. (1982), em que a evapotranspiração (E) pode ser considerada igual à soma da perda por interceptação (I) e por transpiração (T). Isolando-se a perda por transpiração, tem-se a Equação 8:

$T=E-I$

Os dados relativos à precipitação foram obtidos dos pontos de monitoramento do Instituto da Água e da Terra do Paraná (IAT, 2019b). Há dois pontos de monitoramento no município de Matelândia, porém o mais próximo do local estudado está localizado no centro da cidade.

Os dados relativos à evapotranspiração foram retirados do Atlas Climático do Paraná do ano de 2018, emitido pelo Instituto Agronômico do Paraná (IAPAR, 2018). Foi extraída uma média dos valores divulgados nos mapas de evapotranspiração e dos valores relativos aos meses de janeiro a dezembro de 2019.

A vazão (escoamento superficial) $(Q)$ estimada foi encontrada por meio do método racional, em cuja equação para cálculo $Q$ corresponde à vazão da bacia em $m^{3} \cdot h^{-1}$ o valor $l$ é relativo à equação da intensidade de chuvas para um local em $m m \cdot h^{-1}$, o valor $c$ é o coeficiente de escoamento superficial e $A$ é relativo à área da bacia em hectares (Equação 9).

$Q=\frac{C \cdot I \cdot A}{360}$

O método racional é indicado apenas para bacias de pequenas extensões, possuindo assim um tempo de concentração relativamente curto, e essas bacias devem possuir uma área com no máximo $5 \mathrm{~km}^{2}$ e tempo de concentração menor do que 1 hora (FRANCO, 2004). Esse método é o mais indicado e leva seu nome por ser o mais simples e o que é utilizado com maior frequência para pequenas bacias hidrográficas. Tem o objetivo de aplicar um percentual da precipitação no escoamento superficial, que é influenciado pelo tipo e a quantidade de vegetação na área de estudo, pela declividade, pelo tempo de retorno e pelo tipo de solo. Foram coletados os valores relativos a um coeficiente de escoamento de uma área de reflorestamento (Tabela 1) com declividade média de 2 a 7\% e tempo de retorno (TR) de 50 anos (MELLO; SILVA, 2013).

Para o cálculo da vazão pelo método racional, considerou-se a equação da intensidade das chuvas para o município de Cascavel (PR) calculada por Longo, Sampaio e Suszek et al. (2006), em virtude de a distância entre o local avaliado e o município usado pelo autor ser menor que $60 \mathrm{~km}$. A caracterização deste estudo possibilita o uso dessa mesma equação. Em se tratando de obras de engenharia, não se recomenda a elaboração da equação própria para o local a ser implementado. Na utilização da equação, foi calculado o TR em anos e o tempo de concentração (TC) em minutos (Equação 10).

$I_{M \mid N}=\frac{(778,54 . T R)^{0,1729}}{(T C \cdot 9,65)^{0,7204}}$

Tabela 1 - Valores de C para várias superfícies, declividades e tempo de retorno.

\begin{tabular}{l|c|c|c|c|c|c|c}
\multirow{2}{*}{ Superfície } & \multicolumn{7}{|c}{ Tempos de Retorno (anos) } \\
\cline { 2 - 8 } & 2 & 5 & 10 & 25 & 50 & 100 & 500 \\
\hline Asfalto & 0,73 & 0,77 & 0,81 & 0,86 & 0,90 & 0,95 & 1,00 \\
\hline Concreto/telhado & 0,75 & 0,80 & 0,83 & 0,88 & 0,92 & 0,97 & 1,00 \\
\hline
\end{tabular}

Gramados (cobrimento de 50\% da área)

\begin{tabular}{l|l|l|l|l|l|l|l}
\hline Plano (O-2\%) & 0,32 & 0,34 & 0,37 & 0,40 & 0,44 & 0,47 & 0,58 \\
\hline Média (2-7\%) & 0,37 & 0,40 & 0,43 & 0,46 & 0,49 & 0,53 & 0,61 \\
\hline Inclinado (> 7\%) & 0,40 & 0,43 & 0,45 & 0,49 & 0,52 & 0,55 & 0,62
\end{tabular}

Gramados (cobrimento de 50 a $70 \%$ da área)

\begin{tabular}{l|l|l|l|l|l|l|l}
\hline Plano (O-2\%) & 0,25 & 0,28 & 0,30 & 0,34 & 0,37 & 0,41 & 0,53 \\
\hline Média (2-7\%) & 0,33 & 0,36 & 0,38 & 0,42 & 0,45 & 0,49 & 0,58 \\
\hline Inclinado (> 7\%) & 0,37 & 0,40 & 0,42 & 0,46 & 0,49 & 0,53 & 0,60
\end{tabular}

Gramados (cobrimento maior que 75\% da área)

\begin{tabular}{l|l|l|l|l|l|l|l}
\hline Plano (0-2\%) & 0,21 & 0,23 & 0,25 & 0,29 & 0,32 & 0,36 & 0,49 \\
\hline Média (2-7\%) & 0,29 & 0,32 & 0,35 & 0,39 & 0,42 & 0,46 & 0,56 \\
\hline Inclinado (> 7\%) & 0,34 & 0,37 & 0,40 & 0,44 & 0,47 & 0,51 & 0,58
\end{tabular}

Campos cultivados

\begin{tabular}{|l|c|c|c|c|c|c|c|}
\hline Plano (0-2\%) & 0,31 & 0,34 & 0,36 & 0,40 & 0,43 & 0,47 & 0,57 \\
\hline Médio (2-7\%) & 0,35 & 0,38 & 0,41 & 0,44 & 0,48 & 0,51 & 0,60 \\
\hline Inclinado (> 7\%) & 0,39 & 0,42 & 0,44 & 0,48 & 0,51 & 0,54 & 0,61 \\
\hline
\end{tabular}

Pastos

\begin{tabular}{c|c|c|c|c|c|c|c}
\hline Plano (0-2\%) & 0,25 & 0,28 & 0,30 & 0,34 & 0,37 & 0,41 & 0,53 \\
\hline Médio (2-7\%) & 0,33 & 0,36 & 0,38 & 0,42 & 0,45 & 0,49 & 0,58 \\
\hline Inclinado (> 7\%) & 0,37 & 0,40 & 0,42 & 0,46 & 0,49 & 0,53 & 0,60 \\
\hline Florestas/Reflorestamentos \\
\hline Plano (0-2\%) & 0,22 & 0,25 & 0,28 & 0,31 & 0,35 & 0,39 & 0,48 \\
\hline Médio (2-7\%) & 0,31 & 0,34 & 0,36 & 0,40 & 0,43 & 0,47 & 0,56 \\
\hline Inclinado (> 7\%) & 0,35 & 0,39 & 0,41 & 0,45 & 0,48 & 0,52 & 0,58 \\
\hline
\end{tabular}

Fonte: Mello e Silva (2013). 
O tempo de concentração será calculado pela equação de Pickering, forma melhorada da equação de Kirpich (MATA-LIMA et al., 2007). O método foi escolhido por meio da análise das informações correlacionadas na equação. A equação de Pickering utiliza dados de altitude de terreno, diferentemente da equação de Kirpich, que usa a declividade média do terreno, sendo, portanto, mais adequada para a coleta de dados de altitude nos terrenos realizadas nos mapas por satélite que são fornecidos na web.

Para o cálculo do TC, foi adotada a Equação 11:

$T C=\left(0,87 \cdot{\frac{L^{3}}{H}}^{0,385}\right.$

Em que:

$L=$ comprimento da bacia em quilômetros $(\mathrm{km})$;

$H=$ altitude do local em metros (m).

Nessa equação, deve-se considerar que o tempo de precipitação nas bacias hidrográficas e o TC devem ser os mesmos. Para melhor explanar os dois tópicos, pode-se destacar que o TC é o tempo necessário para que a bacia escoe por completo e o tempo de precipitação é o tempo que uma gota de chuva leva para percorrer todo o rio (MELLO; SILVA, 2013).

Para a obtenção dos parâmetros de TR, foi utilizada a Equação 12.

$T R=\frac{1}{1-(1-u)^{1 / n}}$

Em que:

$\mathrm{u}=$ risco assumido para obras de engenharia;

$\mathrm{n}=$ tempo em anos.

Para o cálculo foram adotados os índices correspondentes ao tempo de 50 anos e para a drenagem o fator médio de 25 anos para obras, adotando-se o risco assumido de $87 \%$ (TOMAZ, 2002).

O tempo de retorno é o inverso da probabilidade que se tem de que um determinado fenômeno ocorra novamente. $\mathrm{O}$ fenômeno pode ser, por exemplo, a probabilidade de ocorrência de uma enchente, e nesse caso se deve determinar o tempo médio em que o evento poderá se dar outra vez. Essa informação é de grande importância para a delimitação de diferentes áreas de pesquisa ambiental e hídrica (PRINA; TRENTIN, 2018).

A quantidade de chuvas é algo sempre determinante para qualquer pesquisa hídrica, como também para obras hidráulicas. Sendo assim, tendo como base alguns critérios econômicos, o período de retorno utilizado é em média de 5 a 10 anos, conforme indicam Mello e Silva (2013).

\section{RESULTADOS E DISCUSSÃO}

Os dados necessários para a realização do balanço hídrico foram obtidos para o período de janeiro a dezembro do ano de 2018 por meio do atlas do clima do estado do Paraná e dos dados dos pontos de monitoramento do IAT. A Tabela 2 aponta os resultados do balanço hídrico para o período estudado.

Conforme se pode visualizar na Tabela 2, a precipitação média do período estudado foi de $1.648 \mathrm{~mm}$, o que se pode considerar uma quantidade relativamente boa em milímetros, se comparada com as precipitações de outros anos, conforme o Gráfico 1.
Para a confecção do Gráfico 1, foi pesquisada no IAT a média de chuvas em milímetros para cada ano. O período de 18 anos foi definido pelos autores para dar maior segurança nos dados para a análise.

O Gráfico 2 demonstra os valores que foram obtidos para o balanço hídrico. Os dados estão plotados por períodos e foram extraídos por meio das equações e cálculos descritos na seção sobre materiais e métodos.

Conforme pode ser visualizado no Gráfico 2, coexiste uma forte relação das chuvas com os demais dados (transpiração, evapotranspiração e interceptação) e estes estão proporcionalmente interligados. Na Tabela 3 estão representados os valores obtidos para o cálculo do balanço hídrico.

Pode-se observar também que as estações se encontram bem definidas pelos índices de evapotranspiração. Esse índice é muito inferior nos meses mais frios, principalmente de maio a agosto, e relativamente alto nos meses de novembro, dezembro, janeiro e fevereiro, conforme mostra a Tabela 3.

A evapotranspiração acaba por se reduzir nos períodos de maior precipitação.

A transpiração está correlacionada com a evapotranspiração e a interceptação da cobertura vegetal. Observou-se que esse índice decai nos meses de setembro e outubro, que correspondem aos meses da primavera, ao período de alta floração e vegetação mais densa.

Nos meses de janeiro, fevereiro e março, os valores de evapotranspiração foram elevados em razão da alta média de precipitação.

Nos meses de abril e julho, houve quedas nos valores precipitados, porém os índices de evapotranspiração e transpiração permaneceram altos. Em comparação ao mês de outubro, houve alta precipitação, porém os índices de evapotranspiração foram relativamente baixos.

Tabela 2 - Balanço hídrico do Rio Xaxim.

\begin{tabular}{l|c|c|c} 
& Total em mm & Percentuais (\%) & mm.dia'(dia) \\
\hline Precipitação (P) & 1.648 & 100 & 4,52 \\
\hline Interceptação (I) & 239,95 & 14,56 & 0,66 \\
\hline $\begin{array}{l}\text { Escoamento } \\
\text { superficial (Q) (mm²) }\end{array}$ & 24,15 & $\mathrm{NA}$ & $\mathrm{NA}$ \\
\hline Transpiração (T) & 780,05 & 47,33 & 2,14 \\
\hline Evapotranspiração (E) & $1.020,00$ & 61,89 & 2,79 \\
\hline
\end{tabular}

NA: não considera. Fonte: adaptado de IAT (2019a; 2019b).

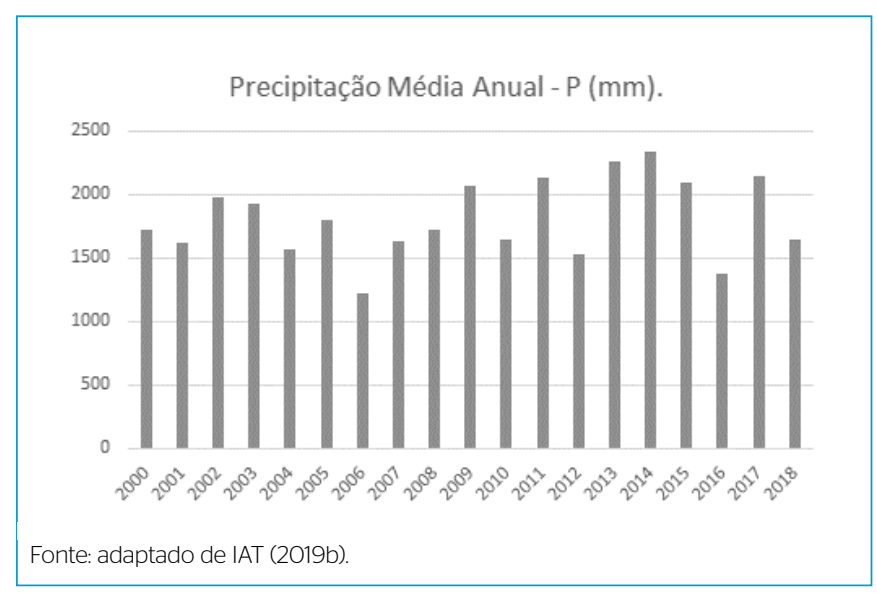

Gráfico 1 - Médias de chuvas anuais para o município de Matelândia 


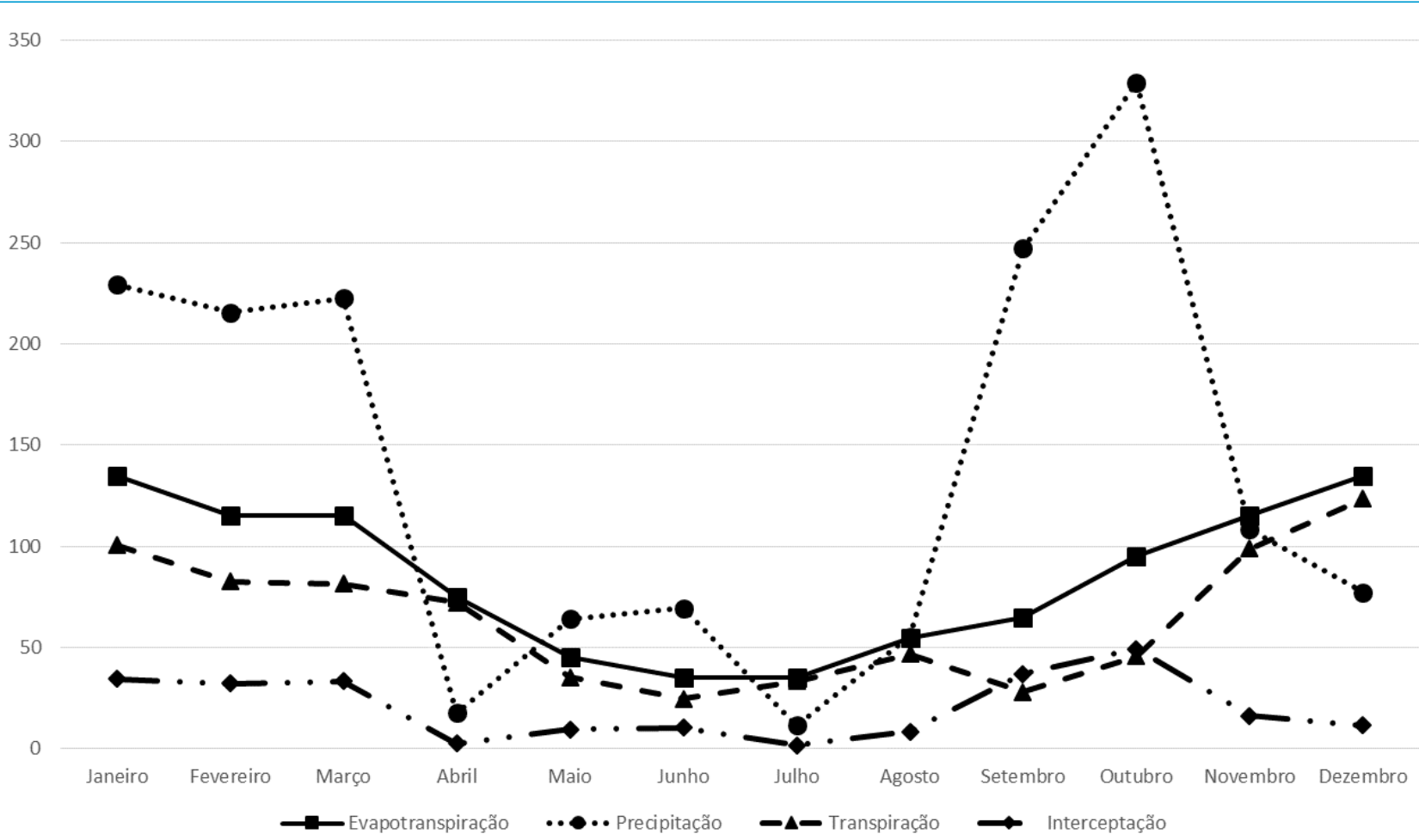

Fonte: adaptado de IAT (2019a; 2019b).

Gráfico 2 - Balanço hídrico.

Tabela 3 - Valores para cálculo de balanço hídrico.

\begin{tabular}{l|c|c|c|c} 
& $\begin{array}{c}\text { Precipitação } \\
(\mathrm{mm})(\mathrm{P})\end{array}$ & $\begin{array}{c}\text { Evapotrans- } \\
\text { piração } \\
(\mathrm{mm})(\mathrm{E})\end{array}$ & $\begin{array}{c}\text { Transpira- } \\
\text { ção }(\mathrm{mm})(\mathrm{T})\end{array}$ & $\begin{array}{c}\text { Intercepta- } \\
\text { ção }(\mathrm{mm})(\mathrm{I})\end{array}$ \\
\hline Janeiro & 229,40 & 135 & 101,60 & 33,40 \\
\hline Fevereiro & 215,60 & 115 & 83,61 & 31,39 \\
\hline Março & 222,60 & 115 & 82,59 & 32,41 \\
\hline Abril & 17,80 & 75 & 72,41 & 2,59 \\
\hline Maio & 64,20 & 45 & 35,65 & 9,35 \\
\hline Junho & 69,60 & 35 & 24,87 & 10,13 \\
\hline Julho & 11,60 & 35 & 33,31 & 1,69 \\
\hline Agosto & 55,40 & 55 & 46,93 & 8,07 \\
\hline Setembro & 246,80 & 65 & 29,07 & 35,93 \\
\hline Outubro & 329,20 & 95 & 47,07 & 47,93 \\
\hline Novembro & 108,40 & 115 & 99,22 & 15,78 \\
\hline Dezembro & 77,40 & 135 & 123,73 & 11,27 \\
\hline Média anual & 1648,00 & 1020 & 780,05 & 239,95 \\
\hline
\end{tabular}

Fonte: adaptado de IAT (2019a; 2019b).

Durante a maior parte do seu trajeto, o Rio Xaxim passa por lavouras. O trecho inicial da área abordada compreende a sua vazão normal de aproximadamente $3.500 \mathrm{~m}^{3} \cdot \mathrm{h}^{-1}$. Os valores foram levantados por meio de uma medição realizada in loco, com a medição da topografia do perfil do rio. Ao sair do trecho estudado, a vazão do Rio Xaxim ganha uma contribuição proveniente do escoamento superficial que pode ser calculada pelo método racional, de $23,27 \mathrm{~m}^{3} \cdot \mathrm{h}^{-1}$, correspondente a $0,66 \%$ da vazão escoada pelo rio.

\section{CONCLUSÕES}

Este estudo foi de grande importância para o conhecimento da região por demonstrar a influência que uma área florestal, mesmo com o plantio de eucaliptos para corte, pode causar em um pequeno trecho de um rio. Foi possível confirmar a possibilidade de cálculo utilizando o método racional, que Franco (2004) e Mello e Silva (2013) destacam como sendo uma forma simples de obtenção dos resultados.

Como a área possui metragem inferior a $5 \mathrm{~km}^{2}$, foi possível empregar o método racional para calcular a vazão de escoamento da área analisada. Por meio deste estudo, pôde-se observar que a área contribui muito pouco no volume de escoamento do Rio Xaxim, com equivalente de contribuição menor que $1 \%$ da vazão total do rio.

Outro ponto a ser observado é que os critérios analisados para a obtenção do balanço hídrico (precipitação, transpiração, evapotranspiração e interceptação) estão proporcionalmente interligados.

Seguindo as análises feitas nas tabelas e gráficos, é possível visualizar que o item analisado que exerce influência nos demais é a precipitação. Contudo, conforme os índices pluviométricos sofrem queda, os outros itens também seguem a mesma tendência, uma vez que estão ligados proporcionalmente. Entre todos os itens analisados para a obtenção do balanço hídrico, o que menos sofre queda acompanhando a precipitação é a transpiração.

Já a evapotranspiração é a mudança de estado da água para o estado gasoso e abrange todo o ciclo hidrológico, desde os espelhos de águas, animais e plantas. Por esse motivo, a relação de proporção que esse item apresenta com relação às chuvas é de grande influência. 
A interceptação é considerada como sendo a parte que fica acima da superfície do solo e que ocorre em consequência da grande quantidade de vegetação e de outras formas de retenção presentes na natureza. Sofre influência direta do índice pluviométrico, porém no ciclo hidrológico corresponde a uma parcela muito pequena do balanço hídrico independentemente da quantidade de chuvas.

Com isso, os autores concluem que o método racional para a obtenção dos valores para balanço hídrico pode ser utilizado, apresentando fácil aplicabilidade e resultados satisfatórios. Pode-se concluir, ainda, que a vazão do Rio Xaxim que foi calculada, mesmo não exercendo uma influência tão marcante nos seus afluentes, é de extrema necessidade para os ecossistemas e para a qualidade ambiental dos seus arredores.

\section{CONTRIBUIÇÕES DOS AUTORES}

Martinhago, D.: Conceituação, Curadoria de Dados, Análise Formal, Investigação, Metodologia, Administração do Projeto, Escrita - Primeira Redação, Escrita Revisão e Edição. Marcolin, J.F.: Conceituação, Curadoria de Dados, Análise Formal, Investigação, Metodologia, Administração do Projeto, Escrita - Primeira Redação, Escrita - Revisão e Edição. Ramallo, P.: Conceituação, Curadoria de Dados, Análise Formal, Investigação, Metodologia, Administração do Projeto, Escrita - Primeira Redação, Escrita - Revisão e Edição. Araújo, E.C.: Análise Formal, Supervisão, Visualização. Sandmann, A.: Análise Formal, Supervisão, Visualização. TONIN P.C.: Análise Formal, Supervisão, Visualização; Schutz, F.C.A.: Conceituação, Metodologia, Administração do Projeto, Supervisão, Validação, Visualização.

\section{REFERÊNCIAS}

AGÊNCIA NACIONAL DAS ÁGUAS (ANA). Hidrologia básica: unidade _1. In: ANA. Acervo educacional sobre a água, 2012. Disponível em: https:// capacitacao.ana.gov.br/conhecerh/handle/ana/2513. Acesso em: 26 ago. 2019

BING. Localização área escolhida para estudo. Bing, 2019. Disponível em: https://www.bing.com/maps?FORM=Z9LH3. Acesso em: 9 set. 2019.

FILL, H.D.; SANTOS, I.; FERNANDES, C.; TOCZECK, A.; OLIVEIRA, M.F. BalançO hídrico da bacia do rio Barigüi-PR. Raega, v. 9, nov. 2005. Disponível em: https://revistas.ufpr.br/raega/article/view/3447. Acesso em: 2 set. 2019. http:// dx.doi.org/10.5380/raega.v9iO.3447

FRANCO, E.J. Dimensionamento de bacias de detenção das águas pluviais com base no método racional. Dissertação (Mestrado) - Universidade Federal do Paraná, Curitiba, 2004. Disponivel em: https://docs.ufpr.br/ -bleninger/ dissertacoes/O85-Edu_Jose_Franco.pdf. Acesso em: 9 set. 2019.

INSTITUTO DA ÁGUAS DA TERRA DO PARANÁ (IAT). Águas Paraná. Curitiba: Instituto das Águas do Paraná, 2019a. Disponível em: http://www. aguasparana.pr.gov.brl. Acesso em: 9 set. 2019.

INSTITUTO DA ÁGUAS DA TERRA DO PARANÁ (IAT). Relatório de alturas mensais de precipitação. Curitiba: Instituto das Águas, 2019b. Disponível em: http://www.sih-web.aguasparana.pr.gov.br/sih-web/ gerarRelatorioAlturasMensaisPrecipitacao.do?action=carregarlnterfacelnic ial. Acesso em: 10 set. 2019

INSTITUTO DE DESENVOLVIMENTO RURAL DO PARANÁ (IAPAR). AtIaS climático do estado do Paraná. IAPAR, 2018. Disponível em: http://www. iapar.br/arquivos/File/zip_pdf/AtlasClimaticoPR.pdf. Acesso em: 9 set. 2019.
LEOPOLDO, P.R.; FRANKEN, W.; MATSUI, E.; SALATI, E. Estimativa de evapotranspiração de floresta amazônica de terra firme. Acta Amazonica, v. 12, supl. 3, 1982. https://doi.org/10.1590/1809-439219821235023

LONGO, A.J.; SAMPAIO, S.C.; SUSZEK, M. Equações de chuvas intensas e precipitação provável para o município de Cascavel-Paraná. Varia Scientia, v. 6, n. 11, p. 119-127, out. 2006.

MATA-LIMA, H.; VARGAS, H.; CARVALHO, J.; GONÇALVES, M.; CAETANO H.; MARQUES, A.; RAMINHOS, C. Comportamento hidrológico de bacias hidrográficas: integração de métodos e aplicação a um estudo de caso. Revista Escola de Minas, v. 60, n. 3, p. 525-536, 2007. https://doi.org/10.1590/ s0370-44672007000300014

MELLO, C.R.; SILVA, A.M. Hidrologia: princípio e aplicações em sistemas agrícolas. Lavras: UFLA, 2013. 455 p.

PRINA, B.Z.; TRENTIN, R. Tempo de retorno de inundações: aplicação metodológica. Geousp Espaço e Tempo, v. 22, n. 3, p. 670-686, dez. 2018. https://doi.org/10.11606/issn.2179-0892.geousp.2018.145266

SARI, V:; PAIVA, E.M.C.D.; PAIVA, J.B.D. Interceptação da chuva em diferentes formações florestais na região sul do Brasil. Revista Brasileira de Recursos Hidricos, Porto Alegre, v. 21, n. 1, p. 65-79, jan./mar. 2016. https://doi. org/10.21168/rbrh.v21n1.p65-79

TOMAZ, P. Cálculos hidrológicos e hidráulicos para obras municipais. São Paulo: Navegar, 2002

TUCCI, C.E.M. Hidrologia: ciência e aplicação. Porto Alegre: UFRGS Faculdade de Agronomia, 2009. 